\title{
QUINO: DEL MUNDO DEL CÓMIC AL MUNDO DE LA FILOSOFÍA
}

JAVIER AGUIRRE ROMÁN

Profesor asociado Escuela de Filosofía Universidad Industrial de Santander, Colombia

NANCY LILIANA VILLAMIZAR MEZA

Profesional adscrita a la Secretaría de Educación del

Municipio de Floridablanca, Santander, Colombia 


\title{
QUINO: DEL MUNDO DEL CÓMIC AL MUNDO DE LA FILOSOFÍA*
}

Resumen: en este artículo se exploran las potencialidades filosóficas del comic a partir de Joaquín Salvador Lavado, "Quino", en su obra artística, Mafalda. Se defenderá la idea según la cual estas potencialidades se despliegan en dos niveles: primero, es posible comprender a Quino desde la perspectiva filosófica de la Teoría Crítica. El segundo nivel se refiere al uso del cómic como herramienta pedagógica de acercamiento a la filosofía por su articulación con los grandes interrogantes de la humanidad.

Palabras clave: cómic, Quino, Filosofía, Teoría Crítica, Pedagogía.

\section{QUINO: FROM THE WORLD OF THE COMIC TO THE WORLD OF PHILOSOPHY}

\begin{abstract}
In this paper we explore the philosophical possibilities of the comic based on the work of Joaquían Salvador Lavado, "Quino", especially his artistic work expressed in the comic "Mafalda". We will argue that those possibilities include at least the following levels: first, Quino's work can be analysed from the perspective of Critical Theory, and, second, the comic can be used as a pedagogic tool to approach philosophy's abstract and universal questions.
\end{abstract}

Keywords: Comic, Quino, Philosophy, Critical Theory, Pedagogy.

Fecha de recepción: diciembre 15 de 2015

Fecha de aceptación: agosto 8 de 2016

Forma de citar: Aguirre, J. y Villamizar, N. (2016). Quino: del mundo del cómic al mundo de la filosofía. Revista Filosofía UIS, 15 (1), 163-188, doi:http://dx.doi.org/10.18273/revfil. v15n1-2016008

Forma de citar (Harvard): Aguirre, J. y Villamizar, N. (2016). Quino: del mundo del cómic al mundo de la filosofía. Revista Filosofía UIS, 15 (1), 163-188.

Javier Aguirre Román: colombiano. Profesor Asociado Escuela de Filosofía, Universidad Industrial de Santander. Doctor en Filosofía, State University of New York.

Correo electrónico: javierorlandoaguirre@gmail.com

Nancy Liliana Villamizar Meza: colombiana. Profesional adscrita a la Secretaría de Educación del Municipio de Floridablanca, Santander, Colombia. Historiadora con Maestría en Filosofía de la Universidad Industrial de Santander.

Correo electrónico: nalivime@gmail.com

* Documento de reflexión no derivado de investigación. 


\section{QUINO: DEL MUNDO DEL CÓMIC AL MUNDO DE LA FILOSOFÍA}

\section{El cómic y sus potencialidades filosóficas}

Los cómics, entendidos como ilustraciones o imágenes en secuencia, pretenden trasmitir información y obtener una respuesta del lector (McCloud, 2009, p. 9). Además de ser una expresión artística, son también una forma de comunicación de masas en la que pueden oírse voces individuales y claramente distinguir su forma de contenido. Incluyen, además, toda la gama de estilos pictóricos, desde el dibujo más realista hasta la más total abstracción. Son el mundo invisible de los símbolos y el idioma en un ejercicio de equilibrio de adición y sustracción, en un continuo baile del tiempo y el espacio, en el que solo se requiere la necesidad de decir algo, el deseo de aprender y la habilidad para saber observar su puesta en escena.

El cómic, como narración escrita, no difiere en lo esencial de lo que puede ofrecer un libro o texto desarrollado literariamente, pero sustituye descripciones que en lo literario quedarían a la imaginación y discreción del lector, por imágenes gráficas particulares que se muestran bajo el prisma del dibujante o artista. Esto se hace a partir de la capacidad de narrar diversos tipos de historias, con diversos niveles de profundidad, experimentación y creación que han cautivado a otros lectores ajenos al perfil del lector de cómic.

Dado su carácter icónico y analógico, su convención y codificación se corresponde igualmente con un poder creador de entretenimiento que le confiere una representación, un desciframiento, un sentido y una relación significante que lo vuelve explícito (Ortega, 2010). Esto es lo que lo convierte en un objeto estético, perceptible por los sentidos e interpretado por nuestra mente; con una interpretación diferente en cada persona, y sin embargo, una comprensión casi universal (McCloud, 2009, p. 205). 
Desde una retrospectiva histórica se puede rastrear el cómic en prácticas artísticas muy antiguas en los cuatro puntos cardinales del planeta (Michel, 1982). En efecto, entre los antecesores de la historieta se pueden contar a las primitivas pinturas rupestres, los dibujos y jeroglíficos egipcios, las representaciones conmemorativas de la Antigua Roma, los retablos medievales e incluso, los dibujos de las civilizaciones precolombinas. Pero quizás los antecedentes más cercanos a la historieta se encuentran con el surgimiento de la imprenta y algunas expresiones de este tipo que comenzaron a elaborarse en Francia a partir de 1820 y que se caracterizaban por narrar pequeños cuentos y aventuras mediante ilustraciones (Giunta, 2013). Posteriormente, junto con el cine, como arte de masas, se da de forma paralela al proceso de industrialización, el desarrollo tecnológico, literario y artístico en una clara exposición decimonónica de la democratización de la imagen visual. Se empezaron a conocer como cartoons, bande dessinée o tebeos para designar desde caricaturas hasta historietas de prensa (Jimenez, 2006), especialmente en países como Alemania, España, Italia, Francia e Inglaterra. Mientras tanto, en Estados Unidos, un interés importante por el mismo surgió a partir de revistas satíricas y al igual que en Europa, ya eran de conocimiento público durante la segunda mitad del siglo XIX a través de las daily strips y los comic books, entre otros, expandiéndose con paso firme durante la primera mitad del siglo XX hasta la aparición y masificación de la televisión y el cine que trajo como consecuencia, una lenta caída del número de lectores de cómics (Massota, 1982, p. 82).

A pesar de esto, se ha dado a la luz a famosos personajes de cómics durante varias generaciones, y sus lectores antiguos y nuevos han visto movimientos en su lenguaje, expresiones interesantes de marcada orientación comercial en el extremo opuesto geográfico (Japón) donde actualmente se produce un sinnúmero de propuestas diferentes de hacer cómic, cuya difusión ha sido masiva y estrechamente vinculada con el anime, o también conocido manga o cómic nipón (McCloud, 2009, pp. 210-212), fenómeno producido después de la postguerra, con toda una estética, narrativa y exposición al público muy especial que se puede evidenciar en personajes como Ogon Bat, Fukuchan, Kimba, Astroboy, Sazaesan, Gekko Kamen (Centella), Cyborg 009, Meteoro, Golgo 13, Doraemon, Mazinger Z, Dr. Slump, Akira, Kaikei Shuten y Dragon Ball (Giunta, 2013 y McCloud, 2009).

En un giro muy interesante, el cómic tradicional ha pasado a ser el atractivo de aquellas personas cuya cotidianidad está ligada a las nuevas tecnologías, dinamismo y color, para quienes el reto actual reside en la creación de cómics digitales o web cómics con una presencia más fluida y alto impacto en las nuevas generaciones. Esto se explica, en parte, por las ventajas que tienen estas tecnologías, tales como marcadores y ampliación de imagen para personas con 
dificultades visuales, o con archivos sonoros que recitan los textos para una mejor comprensión, edición y recreación de la forma y contenido del cómic. ${ }^{1}$

En el caso latinoamericano, la suerte del cómic ha tenido un curso diferente aunque no alejado del contexto mundial. Tradicionalmente se ha asociado con la cultura anglosajona estadounidense por la enorme influencia del cómic norteamericano como arte de masas, y se le ha percibido como una mercancía importada, propia de la sociedad de consumo. En todo caso, esto no ha hecho que el público latinoamericano deje de sentir gran fascinación por los mitos de los superhéroes, las novelas de intriga o los melodramas de factura norteamericana, lo que ha implicado la marginación de los cómics de elaboración propia en cada país al casi completo anonimato.

Por otro lado, en lo referente a los discursos intelectuales de reivindicación cultural de parte de los académicos latinoamericanistas, hay que señalar que muchos de ellos evitaron el cómic pues en varias ocasiones lo percibían ajeno y se limitaron a reconocer autores de forma aislada. En países como Chile, México, Uruguay o Argentina, donde ha existido una notoria producción de cómics, en manos de autores como José Luis Salinas, Arturo del Castillo, Hugo Pratt, Alberto Breccia y Joaquín Salvador Lavado (Quino), entre muchos más, algunos de ellos tuvieron influencias europeas o estadounidenses, ya fuese en humorismos metafísicos, sociológicos o del tipo Mafalda (Massota, 1982, p. 146).

A la par de trabajos en Europa y Estados Unidos como los de Umberto Eco, Benoit Peeters, Robert Harvey, Daniele Barbieri, Viviane Alary, Thierry Groensteen, Jan Baetens, Pascal Lefevre, Harry Morgan, Alain Roukhomovsky, Will Eisner, Scott McCloud y Michel Lafon, por los años 70 y hacia adelante, arrancaron los análisis semiológicos latinoamericanos de Óscar Masotta, Óscar Steimberg y Juan Sustaraín, quienes abrieron en América Latina, y especialmente en Argentina, el discurso teórico-crítico sobre la historieta ${ }^{2}$, al llevar el cómic como discursividad a los modos de funcionamiento ideológico, los sistemas de sus contenidos ideológicos y su rol en el contexto de la dependencia cultural en América Latina, en ensayos sobre Mafalda (Quino), Fontanarrosa y Clemente.

\footnotetext{
Ejemplos de ello, Kevin and Kell, Cyanide and Happiness, Saturday Morning Breakfast Cereal, Xkcd, Sandra and Woo, Homestuck, Gunnerkrigg Court (Estados Unidos), iEh, tío!, El listo, Juanelo, El joven Lovecraft, El Vosque, Runtime-Error, Raruto y 5 Elementos (España), Caballo Negro, Hitlercito, perro, gato y ardilla; Bunsen, SENI, Noveno Piso (México) y Dinami (Argentina). Ver: Ovelar, M. (2009, 17 de septiembre). "La tira cómica se rejuvenece en Internet" y Matos, D. (2011). V de Vigilantes: el cómic en la universidad.

${ }^{2}$ Ver por ejemplo Berone, L. (2009). "El discurso sobre la historieta en Argentina, 19681983".
} 
Desde entonces, aparecen nuevos estudiosos que le han dado un nuevo enfoque crítico y epistemológico al comic. Entre estos, por solo nombrar a algunos, se encuentran Eduardo Romano, Jorge B. Rivera, Carlos Trillo, Alberto Bróccoli, Lucas Berone y Juan Sasturaín, estudiosos del cómic en Argentina, y sobre todo, los ya mencionados Massota y Steimberg. En España, surgen los estudios teóricos de Román Gubern, Luis Gasca, Antonio Lara o Luis Conde, y en algunas revistas temáticas argentinas como Fierro, Comic Magazine o Comiqueando, entre otras más, se hace alusión al cómic latinoamericano y argentino ${ }^{3}$.

En lo que concierne a la filosofía del cómic, los trabajos realizados a la fecha no son muy numerosos aunque sí muy interesantes. De una parte, se ha hecho una colección de ensayos que exploran las formas en que los cómics, tanto en diseño como en contenido, se articulan con preocupaciones filosóficas y viceversa. La construcción cuidadosa que hace el dibujante de un mundo en forma de cómic puede dar ideas sobre el mundo en que vivimos y los autores de filosofía del cómic revelan cómo las cuestiones y preguntas que tienen que ver con los filósofos se pueden encontrar no solo en algún lugar remoto de la academia, sino también en lugares sin pretensiones y de fácil acceso como las historietas.

Preguntas tales como ¿qué es lo bueno?, ¿qué constituye una buena vida?, ¿qué es una buena forma de gobierno?, ¿qué es una buena sociedad?, ¿qué es la verdad?, ¿cuál es la verdad acerca de la realidad?, ¿cuál es la verdad acerca de la condición humana?, ¿cuál es la verdad acerca de la naturaleza del arte? permiten ver cómo el cómic puede explorar y re-examinar auténticas preocupaciones filosóficas. Desde diversas perspectivas críticas, los cómics también discuten temas relacionados con la reacción del público y la censura. Esto muestra cómo los cómics han sido un campo de batalla clave en los debates culturales.

Lo que se conoce en el ámbito de la filosofía del cómic son aquellos pocos trabajos hechos especialmente en Europa y Estados Unidos (McLaughlin, 2005), quizá desde el momento en que Umberto Eco promocionó a la historieta para ser un objeto de estudio "serio" en su obra Apocalípticos e integrados (Eco, 1968). En adelante, se han llevado a cabo análisis filosóficos de cómics (o basados en ellos), como por ejemplo: Para leer al Pato Donald de Ariel Dorfman y Armand Mattelart (Dorfman y Mattelart, 1973), Le Monde d’Hergé (autor de Tintín) por el filósofo francés Benoit Peeters (Peeters, 1983) o Los superhéroes y la filosofía. La verdad, la justicia y el modo socrático de Tom y Matt Morris (Morris y Morris, 2013) y de más reciente factoría, Los Simpson y la Filosofía de William Irwin (Irwin y Skoble, 2010), y Tintín en el país de los filósofos (Tintin au pays des philosophes) en la revista francesa Philosophie Magazine (McLaughlin, 2005).

\footnotetext{
$\overline{{ }^{3} \text { Ver por ejemplo }}$ Crítica de historietas (2013).
} 
Asimismo, se han hecho aportes filosóficos como What If? DC's crisis and leibnizian possible worlds de Jeff McClaughlin, Describing and discarding "Comics" as an impotent act of philosophical rigor de Robert C. Harvey, No Harm in horror, Ethical dimensions of the postwar comic book controversy de Amy Kiste Nyberg, Truth be told. Authorship and the creation of the Black Captain America de Stanford W. Carpenter, Plato, Spider-Man and the meaning of life de Jeremy Barris, Modernity, race and the American superhero de Aldo Regalado, Deconstructing the hero de Lain Thomson, Jean-Paul Sartre meets Enid Coleslaw, Existential themes in ghost world de Laura-Paul Canis, Making the abstract concrete, how a comic can bring to life the central problems of environmental philosophy de Kevin de Laplante, The good government according to Tintin. Long live Old Europe? de Pierre Skilling y Drawn into 9/11, but where have all the superheroes gone? de Terry Kading en Comic as Philosophy (McLaughlin, 2005, p. 7), entre otros.

A su vez, la filosofía ha sido dramatizada gráficamente en cómics, desde las ideas religiosas de India, del Islam, del Cristianismo, así como de la Historia de la Filosofía, por ejemplo, en Action philosophers. The people's choice de Fred Van Lente y Ryan Dunlavey ${ }^{4}$, o las recientes ediciones de cómics sobre filósofos como Foucault is doing the laundry de Auren Kinney y Matt MacFarland y los ya famosos mangas filosóficos como por ejemplo Friedrich Nietzsche. Así habló Zaratustra. El Manga de la Editorial Herder, de una serie de grandes obras de la literatura filosófica convertidas en cómics con especial éxito en el ámbito educativo.

De todo esto se pueden recoger dos ideas fundamentales: primero, cuando se leen cómics, se hace una serie de opciones estéticas y filosóficas. Aunque estas elecciones se conciben generalmente de forma inconsciente, son decisiones reales a las que nos enfrentamos cada vez que se abre la sección de tiras cómicas del periódico, al leer un libro de cómics o al ingresar a un web cómic. Desde el principio, la forma del cómic, su lenguaje y la manera como se entiende, están llenos de dilemas filosóficos.

Una vez que se empieza a analizar el contenido de los cómics se puede hacer frente a sus preocupaciones teóricas, las necesidades e ideas más recónditas, los diferentes puntos de vista y pasiones de sus creadores a través de sus diversas historias, arcos narrativos, estilos de dibujo, comentarios, y simbología. En virtud

\footnotetext{
${ }^{4}$ Algunos de los capítulos de este libro que combina filosofía y cómics son iLucha Superstar de la antigua Grecia! con Nietzsche, All sex especial con Ayn Rand, Autoayuda para los perdedores Ugly estúpido con Freud, Manual de la dominación del mundo con Karl Marx, Maquiavelo y la Cábala, El odio a los franceses con Descartes, La decisión del pueblo con Kierkegaard, La violencia sin sentido especial con Kant, Schopenhauer, Hegel y John Stuart Mill; The lightning round con Diógenes, Lao Tzu, Michel Foucault, David Hume, Confucio, George Berkeley, Francis Bacon, Jean-Jacques Rousseau, Thomas Hobbes, Mary Wollstonecraft, Baruch Spinoza y Gottfried Leibniz. Ver: Van Lente, F. \& Dunlavey, R. The people's choice. Evil Twin Comics, 2005-2007. Action philosophers.
} 
de los valores, estándares y la época que encarnan, los cómics sirven como pequeñas ventanas dentro de nuestras almas, la de nuestros padres, abuelos y bisabuelos. Ellos proporcionan un montón de alimento para el pensamiento y ofrecen mucho más que un mero entretenimiento; son reflejo de nuestros miedos y esperanzas, y proveen un espacio para explorar las preguntas de elección moral, lo bueno y lo malo, y la identidad personal (Natoli, 2009). Es decir, son fuente invaluable de reflexión sobre las preguntas fundamentales de la filosofía. Segundo, la filosofía del cómic, o entender al cómic como una fuente de reflexión filosófica, tiene el más noble objetivo de informar y educar a las personas que pueden o no estar sentados en un aula de clase. Sus lectores y sus estudiosos extraen del cómic lo que consideran significativo y a su vez intelectualmente estimulante sobre el ser humano, convirtiéndolo en una herramienta pedagógica de acercamiento, en nuestro caso, a la filosofía, y de esta última para ampliar su radio de acción como disciplina.

En este artículo hemos querido explorar las potencialidades filosóficas del cómic a partir de un caso concreto, a saber, Joaquín Salvador Lavado, "Quino", y su trabajo artístico expresado en Mafalda. Se defenderá la idea según la cual estas potencialidades se despliegan, al menos, en dos niveles: primero, y este será el tema del acápite siguiente, se propone entender a Quino, al menos en su cómic Mafalda, desde la perspectiva filosófica de la Teoría Crítica ${ }^{5}$. Así, en el siguiente acápite del texto se presentará una propuesta de interpretación de los principales personajes y problemas del cómic Mafalda desde el mencionado enfoque teórico. Posterior a esto, y a manera de conclusión del texto, mostraremos un segundo de nivel de relación entre el cómic y la filosofía. Este tiene que ver con el uso que este y todos los demás cómics pueden tener en la enseñanza de la filosofía. Por tanto, en el apartado final se expondrán las razones que justifican que el cómic sea usado para extraer contenidos filosóficamente relevantes; y a su vez, esto hace que se consideren como una herramienta pedagógica de acercamiento a la filosofía.

\section{Del mundo de la filosofía al cómic de Quino: Quino como filósofo crítico}

"No tiene importancia lo que yo pienso de Mafalda. Lo importante es lo que Mafalda piensa de mí"

(Cortázar citado en "El origen de Mafalda", 2016).

\footnotetext{
${ }^{5}$ Sin lugar a dudas existen muchas lecturas posibles de Mafalda. En este texto queremos contrastarla con (algunos) postulados de (algunos) autores propios de la Teoría Crítica. No queremos señalar con esto que nuestra interpretación sea la mejor o la única forma de entender a Mafalda desde la filosofía. Se trata, no obstante, de una perspectiva que vale la pena considerar y discutir. Este fue uno de los resultados más importantes de nuestra investigación.
}

Revista Filosofía UIS, Vol. 15, No. 1, enero-junio de 2016 pp. 163-188 
Joaquín Salvador Lavado Tejón, popularmente conocido como Quino, es un dibujante argentino, poseedor de un humor tierno pero ácido reflejado en dibujos meticulosos, de trazos finos y precisos. Asociado directamente con Mafalda, sus historietas han sido objeto de diversas lecturas, dentro del espectro de la semiología, la literatura o la sociología y de forma un tanto incipiente también desde la filosofía. Abordar las múltiples creaciones de Quino desde la filosofía política es una tarea que permite tener una visión enriquecedora de su pensamiento. Ir más allá de Mafalda acerca al universo de posibilidades de su genio creativo debido a que ya muy pocos niegan a Quino su pertenencia a la Historia de la Cultura de Masas por su especial impacto a nivel latinoamericano, pero muy pocos también se han atrevido a incluirlo como elemento de estudio de disciplinas consideradas como hermanas mayores por tradición intelectual como por ejemplo, la filosofía, en razón a que la falta de reconocimiento del cómic, a nivel general, está ligada a su discurso, habitualmente de medio de masas, de producción con vista al consumo, por encima del rigor artístico o cognitivo de sus contenidos, lo que desvirtúa su verdadero valor y en consecuencia, su exigua habilidad u oportunidad para realizar tales estudios y para dar a conocer los logros ya obtenidos.

Empero, al leer un cómic de Quino se entra al asunto que nos quiere contar. Su pensamiento y sus personajes terminan por hacer parte de nosotros, y nosotros formamos parte de ellos, en tanto que les re-creamos y les interpretamos. Este fenómeno, observado con detenimiento, deja muchas preguntas: ¿cómo los cómics de su autoría han podido permanecer en la memoria de tantas personas en el mundo entero durante más de 50 años? ¿De qué forma traslada su pensamiento en imágenes? ¿Cómo sus cómics logran comprometerse con la política? Todas estas preguntas se pueden analizar, como se ha hecho, desde diferentes frentes como la semiología, la sociología y la historia del arte. Pero, ¿es posible abrir una discusión desde la filosofía a partir de sus cómics?

En principio, la respuesta afirmativa parece clara en la medida en que son dos clases de saberes que han tocado la vida del ser humano en todos sus aspectos. Como se señaló anteriormente, todo cómic cuenta algo concreto con un significado definido dentro de la sociedad: en la historieta todo significa porque todo es social y moral (Massota, 1982, p. 9). Desde el momento en que se centra la atención en cualquier cómic, nos encontramos con que están llenos de dilemas filosóficos, y una vez que se empieza a analizar su forma y contenido, es posible articularlos a las diferentes preocupaciones de la filosofía y viceversa.

A pesar que se considere al cómic como el pariente pobre del mundo del arte, se puede observar cómo el dibujante-pensador a través de su obra, revela cuestiones y preguntas que inquietan a los filósofos en lugares y formas sin pretensiones, y mejor aún, de fácil acceso. La construcción cuidadosa de un mundo en forma de cómic puede dar ideas sobre el mundo en que vivimos. 
Jeff McLaughlin en su libro Comic as philosophy (2005), señala que quienes han trabajado los cómics en la filosofía han demostrado cómo las preguntas que se hacen los filósofos no sólo se hallan en campos académicos específicos sino que además abren la posibilidad de que el cómic se pueda convertir en herramienta pedagógica en las aulas ${ }^{6}$.

Como segundo aspecto relevante, se ha reconocido ampliamente que los cómics de Quino han sido durante muchos años una lectura sociopolítica de Argentina, tanto como de las tensiones de la modernidad en el mundo contemporáneo latinoamericano (Iglesias, 2000, p. 120). Ellos no son tan inocentes e inofensivos como parecen, sus mensajes no dependen solo de sus dibujos, incluyen en su estructura mensajes sobre preguntas esenciales del ser humano y sobre sus decisiones morales, todo esto en un contexto sociopolítico determinado. Más allá de ser fuente de entretenimiento, sus cómics se han conectado con el mundo como medio de expresión a través de la publicidad en sus diversas posibilidades y han logrado que sus seguidores se proyecten o identifiquen con la forma de pensar de sus personajes. En sus cómics se pueden ver alusiones a las guerras, la corrupción, la injusticia, la desigualdad social, la vejez, la familia, el bien y el mal, la violencia de género, la niñez, la identidad, la crítica al imperialismo y los efectos de la globalización, la identidad, el miedo, la ternura, el uso y abuso del poder, el amor, y por supuesto, la libertad ${ }^{7}$; este último, uno de los temas que le ha merecido a Quino la importancia de hacerla cobrar vida a través de uno de sus más significativos personajes y con quien se siente sumamente identificado ${ }^{8}$.

En este orden de ideas, se debe considerar que existe la posibilidad de encontrar en los cómics de Quino, diversos símbolos, ya en imágenes o en palabras, ya variados o repetidos, que podrían ser sus marcos de referencia y generadores de significado. Pero, un diccionario de filosofía no es el primer lugar donde se esperaría encontrar a Quino, por lo menos no al lado de filósofos como Kant, Descartes o Hegel. No todavía. De hecho, la obra de Quino, como ya se ha dicho, ha sido abordada desde muchos puntos de vista diferentes, pero, ¿qué hay de la filosofía? ¿Es posible rastrear algunas de las preguntas fundamentales de la filosofía política? ¿Se puede considerar a Quino un filósofo político?

\footnotetext{
${ }^{6}$ En palabras de McLaughlin, "The issues and questions that philosophers deal with can be found not just in some remote branch of academia but in unassuming and easily accessible places. In doing so, they achieve the most noble goal of informing and educating individuals who may or may not be sitting in a university classroom. As the eleven authors present you with a variety of philosophical perspectives and draw from what they consider to be philosophically significant comic books and comic book genres, readers will see how these fields may be used to provide intellectually stimulating insight about the other" (McLaughlin, 2005, p. 11).

7 Canal encuentro (2010, mayo 6). Escritores en Primera Persona: Quino.

${ }^{8}$ El País. (2012) "Quino confiesa que prefiere a Libertad que a Mafalda".
} 
Mafalda, la más conocida de las tiras cómicas de Quino, la más querida tal vez, asistió a una época que vivió la Guerra de Vietnam, la carrera espacial, el posicionamiento del discurso de los derechos humanos, el mundo entero simbolizado en un globo que cuida como si fuera una persona enferma ${ }^{9}$. Quino no se identifica totalmente con ninguno de sus personajes a lo largo de los más de 50 años de producción literaria, aunque cada uno tenga trazos de su manera de ser, de pensar y de la época que le correspondió vivir. Es un contestador irreductible, extremadamente preocupado con la situación mundial, un pensador para quien el universo es continuamente observado a partir de dos características fuertes: lo político y la condición humana. Toda su obra sugiere la presencia de una ideología implícita en el habla de los personajes; en ese espacio discursivo actúa, no es simplemente un medio de comunicación "neutral". Para Quino es fácil presentar sus cómics a partir de supuestos estereotipos de ingenuidad, ternura y futilidad, pero dejan entrever, un pensar maduro, crítico, actualizado y lúcido.

Al hacer un balance de sus cinco décadas de trabajo, Quino, "obrero" del dibujo, como se nombra a sí mismo, manifiesta su coherencia ideológica en su perspectiva crítica hacia las relaciones de poder, de explotación de unos a otros: "en 50 años me he mantenido siempre fiel a una temática que en el fondo es la relación de los débiles frente a los poderosos" (Montaño, 2004).

De igual forma, en las tiras cómicas de Quino se puede encontrar una visión escéptica y crítica de las posibilidades reales de la humanidad de "alcanzar la utopía". En palabras de Quino: "No sé en qué creo, no me propongo creencias, sino seguir haciendo cada día lo que he hecho en estos 50 años [...] Espero que algún día se logre una equidad social como la que aparentemente proponía el socialismo, solo que el ser humano con sus ambiciones de poder y sus corrupciones termina echando a perder todo. Espero que aparezca alguna vez un sistema que funcione" (Montaño, 2004).

En una intención por concientizar a un sujeto-masa sobre algún aspecto del sistema político, económico o cultural, llámese democracia o socialismo, Quino parece querer incitar una iluminación a través de su obra al recrear una cotidianidad obvia, demasiado evidente para él como oscura para el sujeto común. Se vale de sus historietas para mostrar que hemos hecho las cosas mal, que nuestra cultura nos lleva al lado contrario de dónde queremos ir, qué cosas "no" somos, en una huida al oscurantismo sin pretensiones particulares por algún determinado sistema político.

\footnotetext{
${ }^{9}$ Ver: Egert, R. y Tirloni, L. (2011).
} 
Visto así, Quino tiene una posición filosófica de denuncia y de crítica, de generar un posicionamiento consciente, de presionar los símbolos para que le hablen a quien duda al resaltar las ambigüedades del acontecer diario y de la condición humana; y, sobre todo, de nombrar, dibujar, simbolizar, en la medida de lo posible, lo que, de otra forma, parece condenado al olvido y al silencio. Todo esto, sin embargo, al margen de un "sistema ideológico-filosófico" compacto y determinado: "Mi drama es que yo no tengo ideas políticas. Me sentiría muy feliz de poder creer en algo. Hay gente que dice que soy marxista, pero jamás leí a Marx, me da vergüenza decirlo, pero es así" (Entrevista a Quino, 1972).

Como lo expone Latxague (2008), la sátira social que Quino construye día a día en sus cómics tiene como punta de lanza la crítica a los defectos y tensiones sociales de la humanidad a través de la enfermedad como tema recurrente y recurso lógico para poner en tela de juicio, las imperfecciones y disfunciones del cuerpo social al introducir una reflexión exhaustiva sobre los problemas globales y su disconformidad con el orden social (Latxague, 2008): "Temo al sufrimiento previo. Me asusta más la enfermedad de la muerte, la cual supongo que es como antes de nacer. La muerte es uno de mis temas recurrentes en mis dibujos. Me atrae como fenómeno inevitable" (Quino y Urwicz, 2012).

Para Quino, la mayor parte del tiempo, "el ser humano es el cáncer del planeta"10, una enfermedad, y como tal, supone que unos procesos vitales de tipo particularmente resonante, doloroso y horrible tienen lugar en un cuerpo que se consume, afectando aleatoriamente a cualquiera de sus órganos, o a todos. El cáncer es una enfermedad de crecimiento interno, a veces visible, anormal, medible, incesante, constante y letal en muchas ocasiones. Como metáfora patológica (Sontang, 2003), Quino señala la insatisfacción, el desequilibrio, la represión, la contraposición entre salud y enfermedad sociales; poderosos y débiles, razón y sinrazón de la condición humana, o humanidad e inhumanidad.

Es el grito de un hombre que sabe que el hombre debe cambiar. La salud vendría a ser la reflexión profunda sobre la cura a la enfermedad de la razón a través de una voluntad férrea de mejorar el estado actual de las cosas por encima de los nuevos totalitarismos: "Viajando he aprendido que la voluntad y la unidad humana pueden modificar muchas cosas. En Egipto he visto gente que no cambia sus usos, que no cae en la desesperación del consumismo. En Cuba he visto lo que pueden la voluntad y la unidad. Aún en la pobreza, con el esfuerzo común se pude conseguir salud, educación, alimentación" (Quino, 2012, p. 13).

10 Pérez y Quino (1999). 
En una fortísima expresión de deseos, Quino considera que el ser humano puede comprender su propia patología. Y es entonces cuando invierte el signo de su arte: crea humor de lo que de por sí no es nada gracioso y lo elabora haciéndolo circular alrededor de la esperanza emancipadora, sabiendo como sabe, que su aporte, el humor, no es más que un testigo lúcido de todo aquello que observa en la sempiterna pregunta por nuestra condición humana, enferma o no: "El ser humano comete bárbaros errores. Pero puede corregirlos. La humanidad no es solo calamidad, Hitler, la lluvia ácida. También es Mozart, también es la medicina. Hoy me parece una arbitrariedad englobar a la humanidad solo dentro de lo malo. Precisamente, yo sobrevivo y no estoy en una silla de ruedas gracias a dos bypass en las piernas. Gracias a esa medicina que es parte de la humanidad" (14).

Quino deja traslucir las recurrencias en sus cómics. Los factores claves de poder comprendidos en relaciones de mutua oposición. Simula una situación que a su vez, oculta y muestra al engañar la mente, esquemas sociales bipolares, antagonismos de las antípodas o a veces antítesis, antinomias, etc. Quino parece mezclar en sus comentarios biográficos un tinte de cinismo expresado en su desprecio a las convenciones sociales e interés en invitar a una trasformación sin decir el tipo, con la ironía como recurso del niño que finge saber o no saber al flotar en la ambigüedad para presionar a que el lector comente. Y es en este sentido, que se podría decir, que él, desde su quehacer profesional, es un productor de pensamiento filosófico. ¿Pero qué clase de pensamiento filosófico político se puede encontrar en Quino?

El recorrido que se ha realizado nos lleva a pensar que los cimientos en los que basa esta mezcla de cinismo e ironía se condensan sólidamente en una postura radicalmente crítica aunque no necesariamente sistemática. Por un lado, los temas de contextualización o recreación artística de su obra pueden casi que volverse estadísticos por la repetición: la enfermedad, el conflicto, la economía capitalista, el autoritarismo, la religiosidad, la ignorancia, etc. Y de otro lado, Quino confronta caracterizaciones estereotipadas de humanos resaltando antinomias, pero a su vez establece la comicidad del malentendido, de la observación ingenua, de la aparente incomprensión o mejor aún, de una comprensión en apariencia equívoca, de los códigos sociales actuados e ideales, entre otros.

Para ello, se plantea entender la propuesta filosófica de Quino en el marco de algunos de los postulados de la Teoría Crítica de la Escuela de Frankfurt ${ }^{11}$. El enfoque general de este artículo puede tener dos limitaciones metodológicas de consideración. La primera es, sin duda, el riesgo de imponer un marco teórico externo al trabajo de Quino en vez de intentar extraer internamente, las preguntas y respuestas filosóficas que se podrían encontrar en su obra. Se considera que a

\footnotetext{
11 Para ser más precisos, de algunos de los pensadores que hacen parte de esta corriente filosófica.
} 
largo plazo, esta última estrategia es la deseable; sin embargo, como un primer acercamiento metodológico, se cree que los resultados de investigación que se presentan en este artículo muestran que es posible leer la obra de Quino desde algunas de las categorías filosóficas propias de la Teoría Crítica. Seguramente hay aspectos de la obra de Quino que se escapan a este intento, pero se defiende lo hecho hasta el momento y presentado en este texto como un ejercicio legítimo de análisis filosófico, el cual, en todo caso, es susceptible de ser mejorado y completado.

La segunda limitación tiene que ver, en contraste, con la naturaleza misma de la perspectiva filosófica escogida. En principio, parecería sumamente contradictorio escoger una propuesta como la de la teoría crítica para tratar de rescatar los elementos filosóficos y críticos que se pueden encontrar en un medio de difusión masivo como lo es el cómic. En este segundo caso es realmente poco lo que se puede decir si se sigue fielmente la conclusión de Adorno según la cual "no cabe la vida justa en la vida falsa". Poca "verdad" se puede encontrar entonces en un producto de la industria cultural. Sin embargo, una vez se considera que el cómic es una obra de arte, y el dibujante, un auténtico artista, como se hace en este caso, nos podemos valer también de la idea, según la cual, las obras de arte son enigmas que dicen, a la vez, que ocultan algo. En este caso, se apuesta por intentar develar esos rasgos emancipatorios y críticos que un objeto industrialcultural oculta.

De esta manera, de la mano de Max Horkheimer (Teoría crítica y crítica de la razón instrumental), y también de Theodor Adorno (Dialéctica de la Ilustración), se recorrerá analíticamente el mundo de Mafalda. También se han considerado las obras de Herbert Marcuse (El hombre unidimensional) y Erich Fromm (El miedo a la libertad), como fuentes de la teoría crítica que soportan esta reflexión. Con ellos se intenta comprender cómo Quino apunta a una crítica profunda de la civilización occidental cuya racionalidad es presentada como una fusión entre dominio y racionalidad tecnológica encaminada a someter tanto a la naturaleza interna como a la externa en la que el individuo es sujeto de sufrimiento y explotación. Y en una doble tarea en las honduras de su corazón, deja traslucir que el principal interés y objetivo de su negatividad crítica es la humanización de la sociedad.

La Escuela de Frankfurt es una corriente de pensamiento e investigación social surgida a partir del Instituto de Investigaciones Sociales de la Universidad de Frankfurt, Alemania, a partir de los años 20 del siglo XX. A ella se acogieron, en varias generaciones, tanto miembros del Instituto como aquellos influenciados por él, tales como Theodor Adorno, Walter Benjamín, Max Horkheimer, Herbert Marcuse, Jürgen Habermas, Oskar Negt, Erich Fromm, Albrecht Wellmer y Axel Honneth, entre otros. Estos autores desarrollaron una teoría crítica de la sociedad contemporánea al responder a cuestiones políticas y problemas teóricos de la 
filosofía moderna y contemporánea, movimientos artísticos y cambios sociales a la luz de las influencias de Marx, Weber, Freud, etc. y de aquellas características propias del periodo histórico que cada uno de ellos, en su particularidad, le tocó asumir. De esta manera, convirtieron a la Escuela de Frankfurt en un importante centro de reflexión sobre las estructuras de dominio presentes en la civilización industrial avanzada que suprimen el potencial emancipador de la sociedad (Entel, Lenarduzzi y Gerzovich, p. 2005).

La teoría crítica pretende, en sus orígenes, contrastar con la teoría tradicional de pensamiento que estaba influenciada por el positivismo, el cientificismo y el marxismo ortodoxo (al cual se propuso interpretar y actualizar) y elaborar una crítica profunda de la civilización occidental cuya racionalidad es presentada como una fusión entre dominio violento y racionalidad tecnológica encaminada a someter tanto a la naturaleza interna como a la externa, en la que el individuo es sujeto de padecimiento, degradación, sometimiento y opresión. Algunos de sus principales representantes y fundadores muestran como principal interés de la teoría crítica, la humanización de la sociedad, la emancipación del ser humano a través de una nueva filosofía y la denuncia de los elementos de dominación y explotación del sistema y consecuente alienación y manipulación del ser humano.

En este orden de ideas, se ha clasificado a Mafalda y a sus amigos según el grado de antinomia de los personajes, de su alienación o emancipación, dentro del marco de los conceptos de razón instrumental y razón autónoma. Se entiende la razón instrumental como la razón truncada, parcial, negativa y cosificadora; razón enferma desde su origen por convertirse en instrumento de dominio de la naturaleza humana y extrahumana que, como principal consecuencia para el ser humano, es su imposibilidad de desarrollarse libremente en todas las facetas de su existencia incapacitándolo para asumir una postura crítica y reflexiva como requisito ineludible de la libertad. En palabras de Horkheimer: "[...] aquella actitud de la conciencia que se adapta sin reservas a la alienación entre sujeto y objeto, al proceso social de cosificación por miedo a caer, en caso contrario, en la irresponsabilidad, la arbitrariedad, y de convertirse en mero juego mental [...] Si quisiéramos hablar de una enfermedad que se apodera de la razón, no debería entenderse esa enfermedad como si hubiese atacado a la razón en un momento histórico, sino como algo inseparable de la esencia de la razón dentro de la civilización, tal como hasta ahora la hemos conocido. La enfermedad de la razón tiene sus raíces en su origen, en el deseo del hombre de dominar la naturaleza, y la "convalecencia" depende de una comprensión profunda de la esencia de la enfermedad original y no de una curación de los síntomas posteriores" (Horkheimer, 1973, p. 105-106).

En contraposición, se entiende como razón autónoma, el instrumento de conciliación entre el hombre y la naturaleza, la evolución del pensamiento humano donde la idea de verdad puede hacerse accesible. "La razón puede 
realizar su racionalidad únicamente mediante la reflexión sobre la enfermedad del mundo tal como la produce y reproduce el hombre; en semejante autocrítica la razón seguirá al mismo tiempo, leal a sí misma, ateniéndose al principio de la verdad, como un principio que únicamente le debemos a la razón, sin buscar ningún otro motivo" (Horkheimer y Adorno, 1998, p. 107). Su expresión se evidencia en la emancipación del ser humano a través de una filosofía que promueve la denuncia de los elementos de dominación y explotación del sistema y la consecuente alienación ${ }^{12}$ y manipulación del individuo. En palabras de Horkheimer y Adorno, "El individuo plenamente desarrollado es la realización cabal de una sociedad plenamente desarrollada. La emancipación del individuo no es una emancipación respecto a la sociedad, sino una superación por parte de la sociedad de la atomización, atomización que puede alcanzar su punto culminante en períodos de colectivización y cultura de masas" (84).

Es de aclarar que como proyección de la condición humana, todos los personajes de Mafalda muestran una personalidad propia. Su participación, activa o pasiva ${ }^{13}$, como instrumentos de la razón, ha permitido observar su tendencia a ciertos rasgos característicos de los seres humanos, pero invariablemente, se pueden encontrar participaciones que eventualmente escapan a su personalidad según la clasificación realizada en este artículo. Dicho esto, nuestra reflexión sobre los cómics se ceñirá al siguiente esquema:

\footnotetext{
12 Se entiende "alienación" como un concepto estrechamente relacionado a los de cosificación y reificación en las ideas iniciales de Karl Marx. En la teoría crítica, el sujeto alienado es aquel individuo que hace parte del engranaje de una sociedad administrada que devora su misma existencia: "cuando los individuos se identifican con la existencia que les es impuesta y en la cual encuentran su propio desarrollo y satisfacción. Esta identificación no es ilusión, sino realidad. Sin embargo, la realidad constituye un estadio más avanzado de la alienación. Esta se ha vuelto enteramente objetiva; el sujeto alienado es devorado por su existencia alienada" (Marcuse, 1993, p. 41).

${ }^{13}$ Se considera una participación activa o pasiva, el grado de compromiso de los personajes estudiados con los elementos de resistencia o sometimiento a la razón instrumental: "el individuo que ofrece resistencia se opondrá a todo intento pragmático por conciliar las exigencias de la verdad con las irracionalidades del existir [...] La sumisión, es aquel hacia el que la mayoría se ve impulsada para cargarlo sobre sí. A pesar de que la mayor parte de la gente no superaría más la costumbre de blasfemar contra el mundo a causa de sus dificultades, aquellos que son demasiado débiles para enfrentarse con la realidad no tienen más remedio que extinguirse identificándose con ella. Nunca se reconcilian racionalmente con la civilización" (Horkheimer y Adorno, 1998, pp. 71-72).
}

Revista Filosofía UIS, Vol. 15, No. 1, enero-junio de 2016 pp. 163-188 
Cuadro 1. Cuadro de personajes de Mafalda de acuerdo a su alienación y emancipación

\begin{tabular}{|c|c|c|}
\hline \multicolumn{2}{|c|}{ Razón instrumental: Alienación } & Razón autónoma: Emancipación \\
\hline Alienados activos: & Alienados pasivos: & $\begin{array}{c}\text { Resistencia a la sugestión } \\
\text { de la razón instrumental: }\end{array}$ \\
\hline
\end{tabular}

Fuente: Villamizar Meza (2013, p. 58)

Mediante este acto de reflexión nos acercamos a lo que Quino anuncia y denuncia a través de sus cómics que pueden ser reflejo de la "enfermedad de la razón" de la sociedad contemporánea, pero a su vez, sueños de esperanza, emancipación y felicidad para la humanidad. En este sentido, nuestro análisis de Mafalda, un clásico de la obra de Quino, permitió observar que Mafalda, Libertad, Guille, los papás de Mafalda, la tortuga Burocracia, Felipe, Miguelito, Susanita y Manolito, se comprenden en relaciones de mutua oposición. Ellos, en el interior del mensaje, solo significan y son significativos a partir de sus diferencias. Ninguno de ellos se comprende sin los otros, y, todos juntos, vistos en su conjunto, apuntan a una crítica profunda de la civilización occidental cuya racionalidad es presentada como una fusión entre dominio y racionalidad tecnológica encaminada a someter 
tanto a la naturaleza externa como interna en la que el individuo es sujeto de sufrimiento y explotación. Fusión y dominio que no son capaces ni siquiera de nombrarse y tematizarse tal y como lo muestra la siguiente afirmación de Susanita al final de la viñeta que presentamos a continuación:

Imagen 1.
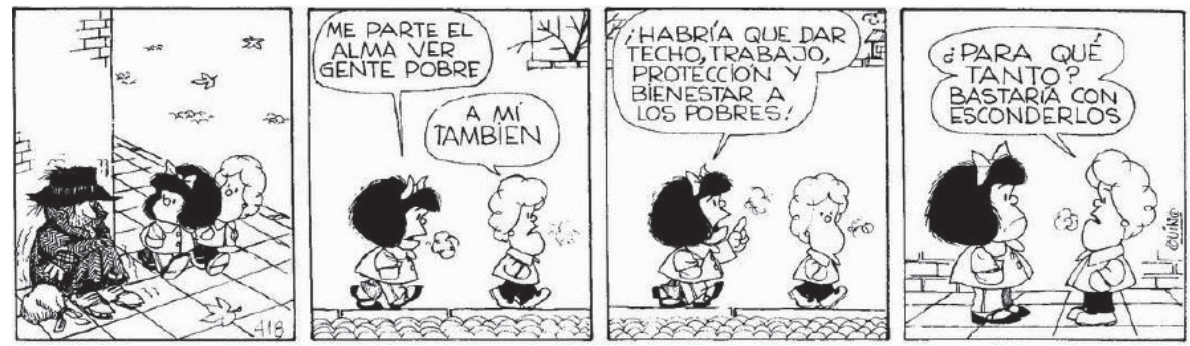

Fuente: Quino (2004, pp. 3-656)

Ante la propuesta de Mafalda de realizar acciones para resolver los problemas de la "gente pobre" y acabar así, con la pobreza, la reacción de Susanita apunta, en cambio, a reforzar las estrategias de enmascaramiento.

Cada personaje creado por Quino es reflejo de la enfermedad de la razón de la sociedad contemporánea, pero, a su vez, son abanderados de posturas emancipadoras. En ellos se evidencia una participación activa o pasiva como instrumentos de la razón: Manolito, Susanita, Miguelito, los padres de Mafalda, Burocracia (la mascota) y Felipe, son la expresión de la alienación, de la razón instrumental. Cada uno de sus pensamientos y acciones están orientados al logro de fines establecidos y controlados por el sistema, de conformidad dentro de la maquinaria social, de defensa del statu quo, de las tradiciones culturales y de los valores burgueses, de la desesperanza del hombre moderno, de las limitaciones de una sociedad cada vez más automatizada, menos humana, más cosificada y alienada.

\section{Imagen 2.}
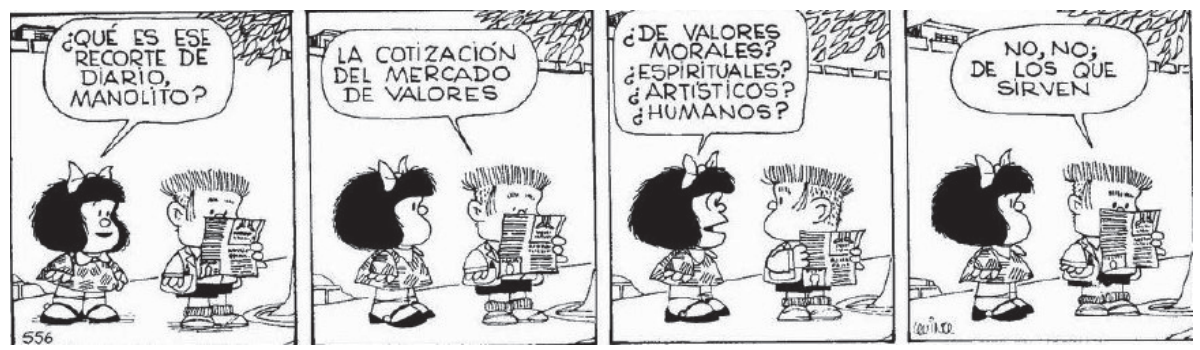

Fuente: Quino (2004, pp. 3-656) 
En este caso, es claro que Manolito reduce los valores, lo valioso, enteramente a lo que tiene valor en un sentido instrumental, "a los valores que sirven" especialmente a los intereses y a las cotizaciones del mercado.

De otra parte, Mafalda, Libertad y Guille, son el proyecto de elaboración de una razón autónoma, el cuestionamiento a la "utilidad" de las convenciones de la sociedad. Podría decirse, que son el concepto positivo de razón, de continua reflexión, y también símbolos de la negatividad crítica, de denuncia de la miseria presente y de la resistencia a la razón instrumental, al conformismo, la esterilidad, la banalidad en cualquier cosa, las irracionalidades del existir, la fragilidad del pensamiento crítico, el predominio de los falsos absolutos y los principios del dominio ciego. Esto lo podemos ver, por ejemplo, en la siguiente viñeta en donde Libertad desenmascara la visión dominante de un "arriba y un abajo" impuesta por la cartografía occidental prevalente.

\section{Imagen 3.}
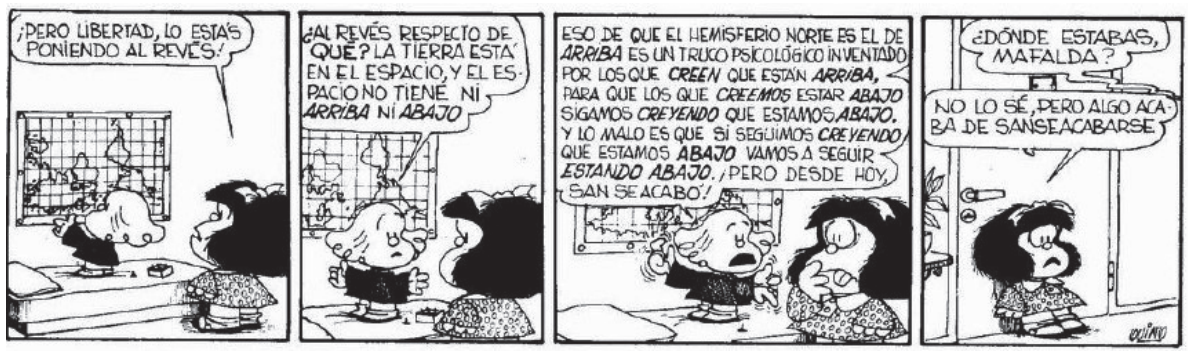

Fuente: Quino (2004, pp. 3-656)

Los temas de contextualización y recreación artística inmersos en la obra se vuelven una constante por su repetición. La crítica a los defectos y tensiones de la humanidad a través de la enfermedad como tema y recurso lógico ponen en tela de juicio las imperfecciones y disfunciones del cuerpo social. Con metáforas patológicas, Quino señala la insatisfacción, el desequilibrio, la represión, la contraposición entre salud y enfermedad social, pero a su vez, considera que el ser humano puede comprender su propio padecimiento. Esto se evidencia en la siguiente caricatura en donde el enfermo en la casa de Mafalda es el mundo entero. 
Imagen 4.
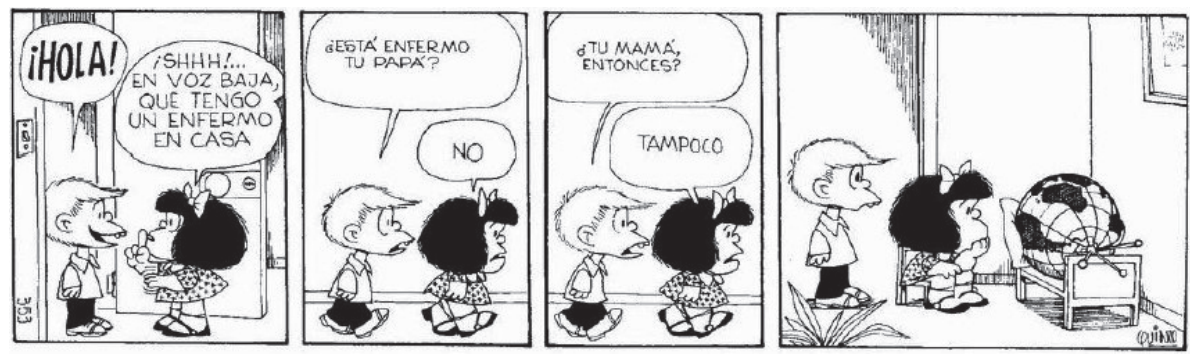

Fuente: Quino (2004, pp. 3-656)

A esta recurrencia en sus cómics se añaden otros temas como el poder, la economía capitalista, el autoritarismo, la religiosidad, la libertad, la ignorancia, la justicia, la vida, etc., en las que se evidencian las antinomias, pero a su vez establece la comicidad del malentendido, de la observación ingenua, de la aparente incomprensión, o mejor aún, de una comprensión en apariencia equívoca, de los códigos sociales actuados e ideales, entre otros.

Al invertir el signo de su arte, Quino, como filósofo crítico, crea humor de lo que de por sí no es nada gracioso. Como arte secuencial, sus cómics permiten oír voces individuales convirtiéndolo en un medio de comunicación privilegiado que promueve toda serie de interrogantes. El cómic de Quino, visto filosóficamente, puede explorar las preocupaciones humanas y re-examinar y generar un mayor compromiso con una forma de arte que por muy largo tiempo estuvo descartada por ser considerada trivial a pesar de que su lenguaje icónico tiene un alcance comunicativo que difícilmente puede lograr otro medio de expresión. Este trabajo puede ser completado por extensión al resto de su obra porque merece una mirada que analice las nuevas creaciones, la forma en que renueva o no su práctica humorística, las variaciones y repeticiones en la evolución filosófica de su pensamiento.

Imagen 5.
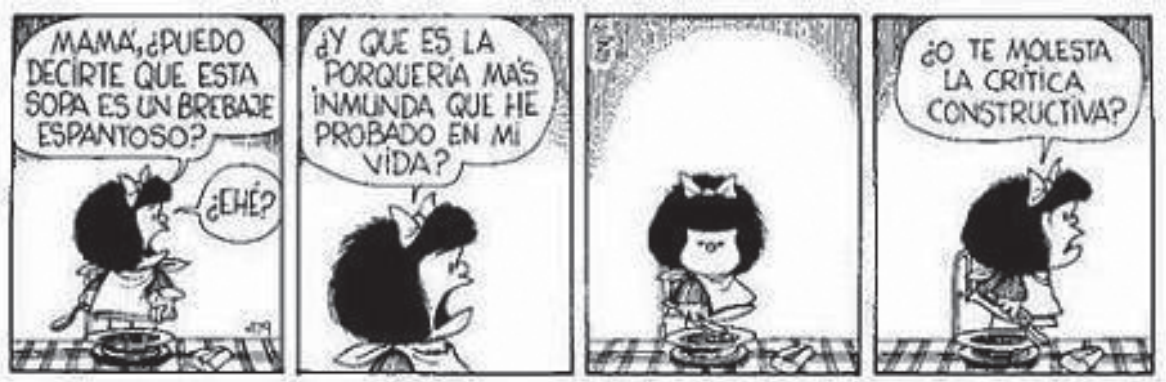

Fuente: Quino (2004, pp. 3-656) 
La típica pregunta de por qué a Mafalda no le gusta la sopa, que es una constante en las historietas de Mafalda, puede ser abordada, desde la perspectiva que trabajamos en este texto, en términos de por qué la vida moderna es una sopa. De esta forma, la pregunta se ve como una alusión a la tesis según la cual el concepto de razón que se halla en la base de la civilización occidental está enfermo por la necesidad humana de dominar la naturaleza. Esta voluntad de dominar la naturaleza, de comprender sus leyes para someterla, ha llegado a reducir al hombre a mero instrumento. A su vez, esta pregunta, que en todo caso podría tener otras interpretaciones, es, con todo, el canal a través del cual Quino nos puede conducir a nuevos interrogantes y a posibles respuestas sobre la condición humana y el problema de nuestra civilización moderna al dejar abierta la posibilidad de cuestionar lo incuestionable de nuestro modo de vida.

\section{Del mundo del cómic de Quino al aula de clase}

"Mafalda fue mi maestra de filosofía. Y debería ser obligatoria en las universidades porque enseña a pensar"

(Saramago, citado en El tiempo, 2004).

La filosofía del cómic y, en su haber, la obra de Quino, posee la noble labor de informar y educar a las personas que pueden o no estar sentadas en un aula de clases extrayendo lo que es filosóficamente significativo en un diálogo enriquecedor con sus lectores. La mayoría de los autores que han trabajado la filosofía del cómic desde una variedad de perspectivas logran extraer de las historietas lo que ellos consideran académicamente revelador del noveno arte para que sus lectores vean cómo estos campos pueden ser utilizados para dar una idea intelectualmente estimulante sobre el otro. Los cómics son una herramienta pedagógica de acercamiento a la filosofía, y a su vez, la filosofía puede hacer uso de ellos para ampliar su radio de acción porque cuenta con una capacidad única de dar cuenta de ciertas informaciones y puede provocar respuestas cognitivas y afectivas relevantes. A menudo proporciona una descripción diferente y más precisa que la prosa filosófica convencional.

Asimismo, el estudio del cómic puede contribuir a focalizar la atención sobre los individuos o los colectivos, lo cual facilitaría el aprendizaje de la filosofía, especialmente de la filosofía práctica y de la educación en general, aplicable a los dibujos (animados o no animados) (Irwin, Conard y Skoble, 2010) debido a que su potencial puede ejercer efectos positivos tanto como negativos, lo cual ameritaría, en todo caso, la mediación del profesor: puede fomentar la ignorancia y los comportamientos reprensibles con tanta facilidad como el buen juicio y el crecimiento personal. 
Pero más allá de ello, el cómic puede ofrecer representaciones precisas de la realidad y cultivar la empatía. No solamente se aprende de una obra porque muestre con precisión a los individuos y se experimenten sentimientos hacia ellos, también se aprende porque promueve nuestra identificación con ellos. ¿Cuántas generaciones en América y Europa llevan en su corazón su simpatía por Mafalda o Felipe?

Fundamentalmente, la función pedagógica de la filosofía del cómic está enraizada en las oportunidades únicas que ofrece cuando el lector resulta absorbido en la historia. Si se lo concibe como un esfuerzo creativo con un anclaje en lo real de donde toma su inspiración, elabora hipótesis y representaciones sobre personajes, lugares y situaciones, el cómic se convierte en una fortaleza que permite conocer la realidad o lo que podríamos o desearíamos de la realidad; expande nuestro conocimiento básico al consentir que aprendamos de experiencias que en lo personal no se tienen, no hemos tenido o desearíamos tener.

El efecto pedagógico del cómic de Quino o de cualquier cómic que sea utilizado como herramienta didáctica, ofrece varias posibilidades de reflexión filosófica. Además, también ofrece caricaturas de nosotros mismos, individuos que poseemos defectos severos y cualidades admirables, que nos permite, desde la distancia que tomamos del personaje, hacer reflexiones sobre problemas fundamentales del ser humano. El efecto hilarante o cómico permite examinar cuestiones serias en términos de las grandes preguntas de la filosofía. Bajo el ropaje del humor se desarman resistencias habituales al matizar problemas espinosos.

La atracción del cómic por su condición de dibujo y pertenencia a la cultura de masas no le impide plantear verdades significativas sino que además, aviva la reflexión sobre un mayor espectro de personas que si se leyera una obra clásica y reverenciada lo cual no implica que sea formalmente superior, en todos los casos. Y aquí es donde radica un gran aporte del cómic a la filosofía: el hecho de llegarle a tantas personas y en diversos modos, se constituye en un viaje de ida y vuelta desde y hasta la filosofía, ya sea como libro de texto convertido en elemento pedagógico construido con unidades didácticas para la enseñanza de la filosofía o del cómic mismo como objeto filosófico constituido como apoyo y motivación, como puente didáctico y como proceso pedagógico desde preescolar hasta la universidad (Barrero, 2002). 
Imagen 6.

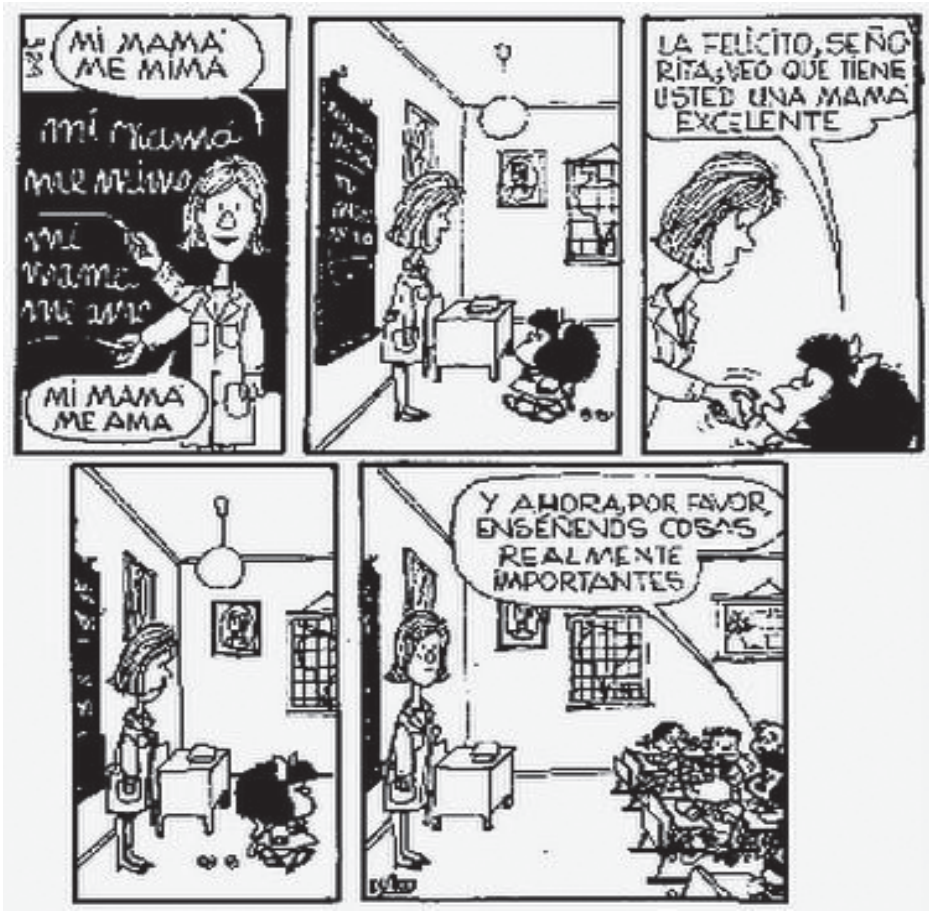

Fuente: Quino (2004, pp. 3-656)

La inmutabilidad de algunos de los personajes de Quino, bien sean sus famosos náufragos, o en este caso los de Mafalda y su amigos, permite sumergirnos en su mundo filosófico-crítico, lo cual conduce a la reflexión, a pensar en el mensaje de la representación propuesta por el dibujante filósofo.

Y tal reflexión puede dar lugar a una comprensión general más amplia así como a un progreso ético si se dan por descontado las ventajas evidentes en su aplicación en el aula de clases, que ya se han mostrado, pero que implica la necesidad de eliminar de manera progresiva y continua la resistencia al cómic en el ambiente académico por la novedad como objeto filosófico en parte debido a la falta de reconocimiento del rigor artístico o cognitivo de sus contenidos, lo cual desvirtúa su verdadero valor como herramienta pedagógica y a las pocas experiencias significativas que han avalado su efectividad (Navarro, 2013).

El reto está planteado y el camino es largo pero la puerta está abierta para la creación y fortalecimiento de nuevos espacios de exploración en la filosofía del cómic, como se pudo apreciar aquí intentando comprender a Quino, desde una perspectiva filosófica por su articulación con los grandes interrogantes de la 
humanidad al servicio de nosotros mismos y nuestros congéneres, y también, por qué no, por su gran potencialidad como herramienta pedagógica que permitiría desarrollar capacidades en nosotros para actuar en el mundo afrontando toda clase de retos, y en todos los planos posibles de la vida personal y social $\varphi$

\section{REFERENCIAS}

Dorfman, A. \& Mattelart, A. (1973). Para leer al Pato Donald. Comunicación de masas y colonialismo. Buenos Aires: Siglo XXI.

Eco, U. (1968). Apocalípticos e integrados ante la cultura de masas. Madrid: Lumen.

Entel, A., Gerzovich, D. y Lenarduzzi, V. (2005). Escuela de Frankfurt. Razón, arte y libertad. Buenos Aires: Eudeba.

Horkheimer, M. (1973). Crítica de la razón instrumental. Buenos Aires: Sur.

Horkheimer, M. \& Adorno, T. (1998). Dialéctica de la llustración. Madrid: Trotta.

Irwin, W., Conard, M. \& Skoble, A. (2010). Los Simpson y la filosofía. Barcelona: Blackie Books.

Jiménez Varea, J. (2006). El contexto de la historieta. Ámbitos, (15), 121-209.

Marcuse, H. (1993). El hombre unidimensional. Buenos Aires: Planeta.

Massota, Ó. (1982). La historieta en el mundo moderno. Barcelona: Paidós.

McCloud, S. (2009). Entender el cómic: el arte invisible. Madrid: Astiberri.

McLaughlin, J. (2005). Comic as philosophy. USA: University Press of Mississippi.

Morris, T. \& Morris, M. (2010). Los superhéroes y la filosofía. La verdad, la justicia y el modo socrático. Barcelona: Blackie Books.

Natoli, C. (2009). "The Spirit of Comics". Philosophy now, 73, 4-4.

Peeters, B. (1983). Le monde d'Hergé. Tournai: Casterman.

Quino (2004). Mafalda Toda. Buenos Aires: Ediciones de la Flor.

Quino. (2012). 10 años con Mafalda. Buenos Aires: Ediciones de La Flor.

Sontang, S. (2003). La enfermedad y sus metáforas. Buenos Aires: Sudamericana. 
Villamizar Meza, N. (2013). ¿Por qué la vida es una sopa? Quino Filósofo Político. Bucaramanga: UIS.

\section{CIBERGRAFÍA}

Barrero, M. (2002). Los cómics como herramientas pedagógicas en el aula. Recuperado de http://www.tebeosfera.com/1/Hecho/Festival/Jerez/Conferenciajerez020223. pdf. (Consultado el 13 de febrero de 2013).

Berone, L. (2009). "El discurso sobre la historieta en Argentina, 1968-1983". Diálogos de la comunicación, (78), 1-9. Recuperado de http://dialogosfelafacs.net/ el-discurso-sobre-la-historieta-en-argentina-1968-1983/

Crítica de historietas. (2013). Recuperado de http://www.picasesos.ahiros.com.ar/. (Consultado el 2 de marzo de 2013)

Egert, R. y Tirloni, L. (2011). “El discurso ideológico de Mafalda en las historietas de Quino". En el II Congreso Internacional de Enseñanza de Español como Lengua Segunda y Extranjera: Problemáticas de la Enseñanza de ELE hoy. Buenos Aires: Universidad del Salvador.

El País. (2012) "Quino confiesa que prefiere a Libertad que a Mafalda". Recuperado de http://www.elpais.com.co/elpais/entretenimiento/noticias/quinopadre-mafalda-admite-sus-80-anos-su-inclinacion-por-libertad (15 de septiembre de 2013).

Encuentro de Escritores en Primera Persona: Quino. Recuperado de http://www. youtube.com/watch?v=BeqCMiGuxzA. (Consultado el 20 de mayo de 2013)

Entrevista a Quino. (3 de diciembre de 1972). La opinión cultural. Recuperado de http://www.elhistoriador.com.ar/entrevistas/q/quino.php. (Consultado el 6 de junio de 2013).

Giunta, N. Mafalda y Compañía. La historia del cómic. Recuperado de http://www. todohistorietas.com.ar/historia.htm. (Consultado el 3 de febrero de 2013)

Iglesias, L. (2000). "Quino, el humor libre". Correo de la UNESCO. Recuperado de http://museodiogenestaborda.blogspot.com.co/2009/03/quino-el-humor-libreentrevista.html

La nota curiosa: el origen de Mafalda. (Septiembre, 2016). Culturizando. Recuperado de www.culturizando.com/nota-curiosa-el-orgien-de-mafalda/ (Consultado 27 de octubre de 2016). 
Latxague, C. (2008) Modalidades y trasformaciones de la metáfora de la enfermedad en la obra de Quino. Recuperado de http://cle.ens-lyon.fr/espagnol/la-enfermedaden-la-obra-de-quino-43798.kjsp. (Consultado el 15 de marzo de 2013).

Mafalda cuarentona.(Octubre, 2014). Diario El tiempo. Recuperado de www. eltiempo.com/archivo/documento/NAB-1585504

Matos, D. (2011). V de Vigilantes: el cómic en la universidad. Recuperado de http://www.zonanegativa.com/?p=30702. (Consultado el 3 de febrero de 2013).

Michel, P. (1982). Las historietas conquistan el mundo. El correo de la Unesco, (Año XXXV). Recuperado de http://unesdoc.unesco.org/ images/0007/000747/074717so.pdf. (Consultado el 3 de febrero de 2013).

Montaño, E. (2004, 26 de octubre). <<Deplora Quino "el retorno del imperialismo y el oscurantismo" $>>$ Recuperado de http://laventana.casa. cult.cu/noticias/2004/10/26/deplora-quino-el-retorno-del-imperialismo-y-eloscurantismo/ (Consultado el 15 de mayo de 2013).

Navarro, D. Cómic, currículum en la escuela secundaria y APPS. Recuperado de http://art2investigacion-en.weebly.com/uploads/2/1/1/7/21177240/navarro_ diego.pdf (Consultado el 13 de febrero de 2013).

Ortega, S. (2010). Cómic y filosofía. Recuperado de http://filotecnologa.files. wordpress.com/2011/06/comic-y-filosofia_silvia-ortega.pdf. (Consultado el 25 de enero de 2013).

Ortoli, S. (2010). Tintin au pays des philosophes. Philosophie Magazine. Bélgica: Éditions Moulinsart.

Ovelar, M. (2009, 17 de septiembre). La tira cómica se rejuvenece en Internet. El País. Recuperado de http://elpais.com/diario/2009/09/17/ ciberpais/1253154265_850215.html. (Consultado el 3 de febrero de 2013).

Pérez, A. y Quino (1999). Quino en su tinta. La Nación, Costa Rica. Recuperado de http://wvw.nacion.com/dominical/1999/mayo/30/dominical0.html (Consultado el 1 de julio de 2013)

Urwicz, T. (2012). <<Quino: "siempre he sido un francotirador" $>>$. El País. Recuperado de http://historico.elpais.com.uy/suple/ds/12/09/23/sds_665277.asp (Consultado el 23 de septiembre de 2012).

Van Lente, F. \& Dunlavey, R. (2005-2007). Action Philosophers. The people's choice. Issue 6. New York: Evil Twin Comics. 